\title{
A DECOLONIEDADE DOS POVOS BANTU E A LUTA NO CHÃO DA ESCOLA: Uma experiência de intervenção
}

THE DECOLONIEDITY OF THE BANTU PEOPLE AND THE STRUGGLE ON THE SCHOOL FLOOR: An intervention experience

\section{LA DECOLONIEDAD DEL PUEBLO BANTU Y LA LUCHA EN EL PISO ESCOLAR: Una experiencia de intervención}

\section{Wudson Guilherme de Oliveira ${ }^{1}$}

RESUMO: O texto tem como propósito apresentar uma análise decolonial (WALSH, 2013) referente as diferentes características e contribuições dos Povos Bantu em obras literárias e acadêmicas afro-brasileiras (LOPES, 2011), (LWANGA-LUNYIIGO e VANSINA, 2010) como forma de corroborar com a construção da identidade de jovens negros (GOMES, 2010), como medida de enfrentamento às diversas situações desfavoráveis das populações negras, que perpassam pelo cotidiano do Chão da Escola, que são propagados pelos padrões eurocêntricos (MACHADO e OLIVEIRA, 2018) e na discriminação racial (KOMINEK e VANALI, 2018). Todavia, buscamos debruçar nossas reflexões em publicações acadêmicas (MARQUES e NOGUERA, 2013) e livros de literaturas infantis e infanto-juvenis (OLIVEIRA, 2013), que articulam com as perspectivas da Lei Federal 10.639/2003 que torna obrigatório o ensino da História e Cultura dos Povos Africanos e a sua Diáspora no Brasil, em todos os currículos escolares. Posteriormente, iremos analisar um breve estudo de caso, de como foram implementadas as Leis contidas no Artigo 26-A da LDBEN em uma instituição privada localizada no Estado do Rio de Janeiro, a partir de oficinas/aulas de sensibilização, contação de histórias, exposição de livros de Literatura Africana, Indígena e Afro-brasileira e Rodas de Diálogos, na qual foram desenvolvidas como estratégias para a elevação da autoestima das crianças negras (MUNANGA, 1996), o resgate da identidade, propagação da diversidade cultural e o incentivo à leitura, para a redução do racismo na conjuntura atual do país.

PALAVRAS-CHAVE: Decoloniedade. Povos Bantu. Lei Federal 10.639/03.

ABSTRACT: The text aims to present a decolonial analysis (WALSH, 2013) referring to the different characteristics and contributions of the Bantu Peoples in Afro-Brazilian literary and academic works (LOPES, 2011),

Submetido em: 15/12/2020 - Aceito em: 18/02/2021 - Publicado em: 12/07/2021

\footnotetext{
${ }^{1}$ Mestrando em Educação pelo Programa PPGEduc/UFRRJ. Desenvolve vivências como Docente das disciplinas de História, Filosofia, Sociologia e Geografia nos anos finais do Ensino Fundamental, Ensino Médio, EJA Educação para Jovens. Atua também como Pesquisador, Palestrante e Oficineiro. Possui de modo voluntário um "Projeto de sensibilização às histórias Africanas e Afro-Ameríndias através das literaturas".

E-mail: wudafrica@gmail.com
} 
(LWANGA-LUNYIIGO and VANSINA, 2010) as a way to corroborate with the construction of the identity of young blacks (GOMES, 2010), as a measure of coping with the different unfavorable situations of black populations, which permeate the daily lives of school floor, which are propagated by Eurocentric standards (MACHADO and OLIVEIRA, 2018) racial discrimination (KOMINEK and VANALI, 2018). However, we seek to focus our reflections on academic publications (MARQUES and NOGUERA, 2013) and books on children's and children's literature (OLIVEIRA, 2013), which articulate with the perspectives of Federal Law 10.639 / 2003 which makes the teaching of History and Culture of African People and their Diaspora in Brazil, in all school curricula. Subsequently, we will analyze a brief case study of how the Laws contained in Article 26-A of LDBEN were implemented in a private institution located in the State of Rio de Janeiro, from awareness workshops / classes, storytelling, exposure of African, Indigenous and Afro-Brazilian Literature books and Round Dialogues, in which they were developed as strategies for raising the self-esteem of black children (MUNANGA, 1996), rescuing identity, spreading cultural diversity and encouraging reading, to reduce racism in the country's current situation.

KEYWORDS: Decolonity. Bantu people. Federal Law 10.639 / 03.

RESUMEN: El texto tiene como objetivo presentar un análisis descolonial (WALSH, 2013) referente a las diferentes características y contribuciones de los Pueblos Bantu en las obras literarias y académicas afrobrasileñas (LOPES, 2011), (LWANGA-LUNYIIGO y VANSINA, 2010) como una forma corroborar con la construcción de la identidad de los jóvenes negros (GOMES, 2010), como medida de afrontamiento de las diversas situaciones desfavorables de las poblaciones negras, que permean la vida cotidiana de Chão da Escola, que se propagan por estándares eurocéntricos (MACHADO y OLIVEIRA, 2018) y en discriminación racial (KOMINEK y VANALI, 2018). Sin embargo, buscamos enfocar nuestras reflexiones en publicaciones académicas (MARQUES y NOGUERA, 2013) y libros de literatura infantil y juvenil (OLIVEIRA, 2013), que se articulan con las perspectivas de la Ley Federal 10.639 / 2003 que hace que la enseñanza de la Historia y la Cultura de los africanos y su diáspora en Brasil, en todos los planes de estudios escolares. Posteriormente, analizaremos un breve estudio de caso de cómo se implementaron las Leyes contenidas en el Artículo 26-A de LDBEN en una institución privada ubicada en el Estado de Rio de Janeiro, desde talleres / clases de sensibilización, cuentacuentos, exhibición de africanos, indígenas y Libros de literatura afrobrasileña y diálogos redondos, en los que se desarrollaron como estrategias para elevar la autoestima de los niños negros (MUNANGA, 1996), rescatar la identidad, difundir la diversidad cultural y fomentar la lectura, para reducir el racismo en la situación actual del país.

PALABRAS CLAVE: Decolonidad. Pueblo Bantu. Ley Federal 10.639 / 03.

\section{A DECOLONIEDADE dOS POVOS BANTU² E A LUTA NO CHÃO DA ESCOLA: Uma experiência de intervenção}

A busca de outros modos de subjetivação que rompam os paradigmas instituídos pelo dispositivo de racialidade situa-se como demanda para educação e para a produção de conhecimento. Aí se evidencia, ainda, a disputa da verdade histórica como um campo de batalha fundamental para alterar

\footnotetext{
${ }^{2}$ Nei Lopes (2011, p. 179) afirma que é um "Vocábulo que pode ser usado nas formas flexionadas - "banto", "banta", "bantos", "bantas" - ou sem flexões - "bantu" -, forma que designa cada um dos membros da grande família etnolinguística à qual pertenciam, entre outros, os escravos no Brasil chamados angolas, congos, cabindas, benguelas, moçambiques etc".
} 
os pressupostos da dominação racial e viabilizar outras subjetivação.

(SUELI CARNEIRO $\left.{ }^{3}, 2005\right)$.

\section{INTRODUÇÃO}

A epígrafes apresenta os vários significados da oficina pedagógica que será exibida, neste trabalho/oficina, onde foi recheado de sensibilizações, transformações e experiências.

Este artigo objetiva trazer reflexões referentes aos entraves ligados aos episódios de racismo 4 ocorridos no Ambiente Escolar, onde o material pretende amostrar as atividades pedagógicas atreladas as aulas da Disciplina de História, como forma de reduzir os impactos racistas dentro deste espaço de saber.

As ações foram planejadas, preparadas e realizadas de modo solitário. No entanto precisamos informar que a Coordenadora de História, recebeu, analisou e aceitou a execução do projeto pedagógico. Onde apenas contribuiu com visitas exporádicas durante o decorrer das atividades.

As atividades foram desempenhadas em um estabelecimento de ensino privado muito conceituado, localizado em um bairro metropolitano do Estado do Rio de Janeiro que não terá maiores referencias, como método de salvaguardar o progresso da pesquisa. Á vista disso, escolhemos um nome imaginário "Educandário Carolina Maria de Jesus" heroína afrodescendente ${ }^{6}$.

\footnotetext{
${ }^{3}$ CARNEIRO, Sueli. “A Construção do Outro Como Não-Ser Como Fundamento do Ser”. Tese de Doutorado em Educação, Universidade de São Paulo, 2005, p. 301.

${ }^{4} \mathrm{O}$ racismo está longe de ser "uma questão dos negros e das negras" e de outros grupos discriminados. Ele é fruto das desigualdades existentes nas relações sociais entre pessoas brancas e grupos constituídos por pessoas negras, imigrantes, indígenas, ciganas, migrantes etc. superá-lo é um desafio e responsabilidade de toda a sociedade (CARREIRA e SOUZA, 2013, p. 33).

${ }^{5}$ Lembramos que Carolina Maria de Jesus foi uma escritora negra, que trabalhava como ex-catadora de lixos que conheceu e viajou o mundo a partir da sua produção textual, que não se resume aos seus diários publicados, mas também nas variadas formas de manifestações literárias. É surpreendente como tudo se iniciou através de narrativas autobibliográficas, como as afirmações de Dinha e Raffaella Fernandez (2014, p. 17) que apresentavam em suas escritas os impactos das mobilizações políticas contra a expulsão de habitantes dos cortiços, primeiras moradas dos migrantes que chegavam à "cidade da garoa" nos anos de 1940, até a sua própria entrada no Canindé, em uma das primeiras favelas que surgiram a partir do processo de deslocamento, para fora do centro de São Paulo, desse contingente de excluídos. JESUS, Maria Carolina de. “Onde estaes felicidade?” In: DINHA. FERNANDEZ, Raffaella (org.) - São Paulo: Me Parió Revolução, 2014.

${ }^{6}$ Termo modernamente usado no Brasil para designar o indivíduo descendente de africanos, com qualquer grau de mestiçagem, correspondendo ao African-American dos estadunidenses (LOPES, 2011, p. 57).
} 
O estabelecimento referido, está localizado em um bairro de classe média, e tinha como públicos alvos, estudantes das classes elitistas média e média alta, onde se orgulhavam em terem em seus quadros de Alunos, os filhos de empresários cariocas, cantores, artistas e celebridades, de variadas origens étnicas e nacionalidades. Oferecendo uma educação que assegurava o processo de ensino e aprendizagem na Educação Infantil, Ensino Fundamental I, Ensino Fundamental II, Ensino Médio e EJA (Educação para Jovens e Adultos), no qual lecionei como Professor da Disciplina de História nas turmas do $6^{\circ}$ Ano do Ensino Fundamental.

A alegação para a escolha da ação afirmativa $^{7}$ foi a execução da Lei Federal no ${ }^{0} 10.639$ de $2003^{8}$, que alterou a LDBEN (Lei de Diretrizes e Bases da Educação Nacional), que instaurou de modo vital o ensino das Histórias e Culturas Africanas e Afro-brasileiras no Ensino Básico. A Lei em questão vem com a meta de alterar a anterior de $\mathrm{n}^{\circ}$ 9.394, de 20 de dezembro de 1996, sustentada e expandida nos artigos 26-A, 79-A e 79-B, como forma de organizar e diminuir as consequências tensas ocorridas pelos episódios desestruturantes nos espaços de educação, para suplantar os preconceitos ${ }^{9}$, as intolerâncias religiosas, as discriminações ${ }^{10}$ e o racismo ${ }^{11}$ no Chão da Escola.

Com base na Lei, a oficina pedagógica vem com a expectativa de despertar a construção de um observar decolonizado refletido sobre a História e Cultura da África, dos Africanos e dos Afrobrasileiros nos bancos escolares, enriquecendo as relações étnico-raciais, visto que, até este momento encontramos entraves de avanços das Leis em questão, apropriados as práticas aprofundadas em metodologias fundamentadas no eurocentrismo ${ }^{12}$ e nas performances do racismo, invisibilizando situações negativas à diversidade étnica nas Salas de Aulas.

\footnotetext{
${ }^{7}$ Nei Lopes explica que "Ações Afirmativas" são "política pública voltada à promoção da mobilidade social ascendente de membros de um grupo historicamente em desvantagem ou discriminado. Em relação aos afrodescendentes, especificamente, expressa-se, por exemplo, na disponibilização de vagas em universidades, em empresas ou em órgãos públicos, bem como de bolsas de estudo, treinamentos especiais e outras formas propiciatórias de ascensão social, como compensação pelas dificuldades encontradas em um contexto social notoriamente adverso" (LOPES, 2011, p. 35).

${ }^{8}$ Em 11 de Março de 2008 a Lei 10.639/2003 foi substituída pela criação da Lei 11.645/2008 que torna obrigatório, também, o ensino ligado à História e Cultura dos Povos Indígenas nos currículos oficiais da educação nacional.

${ }^{9}$ Nas palavras de Nei Lopes (2011) “Atitude desfavorável para com um grupo ou indivíduos que nele se inserem, baseada não em seus atributos reais mas em crenças estereotipadas. O preconceito racial é uma das molas propulsoras do racismo".

10 “Ocorre discriminação, sempre que alguém movido por sentimento de preconceito e/ou racismo, age causando prejuízos físicos, morais, econômicos, psicológicos, sociais e culturais a pessoas ou grupos" (KOMINEK e VANALI, 2018, p. 88).

${ }^{11}$ Racismo é crime segundo a legislação brasileira. Lei 7.715/89.

12 “visão de mundo que coloca a Europa como modelo, como padrão, centro (povo, culturas, conhecimentos, línguas, etc.) do mundo, tendo seu modo de vida como superior. Privilegia uma única etnia como modelo da humanidade" (MACHADO e OLIVEIRA, 2018, p. 69).
} 
No entanto, para o triunfo desta moção, foi planejada a ação pedagógica "Os Povos Bantu e suas Contribuições Decoloniais no Chão da Escola”, no qual a laboração foram as particularidades culturais e geográficas do extenso Continente Africano, e dele as colaborações trazidas para o Brasil pelos grupos da etnia ${ }^{13}$ Bantu, com a finalidade de favorecer a consolidação da identidade ${ }^{14}$ e da autoestima ${ }^{15}$ dos Alunos afro-brasileiros ${ }^{16}$, somada a ascensão da estima à nossa ascendência africana por parte dos Alunos negros ${ }^{17} \mathrm{e}$ os não negros, como modo de desenvolver a vigente ação sobre as etnias africanas que vieram para o Brasil, cujo a presença é identificada em nossa cartografia, porém, suas múltiplas heranças culturais ainda imperceptíveis em nossa sociedade.

Nas aulas da Disciplina de História, em uma classe do $6^{\circ}$ Ano do Ensino Fundamental, formada por jovens Alunos negros (as), pardos (as ${ }^{18}$ e brancos (as), na atmosfera de uma instituição de ensino privada na cidade do Rio de Janeiro. Onde Testemunhamos uma pedagogia decolonial ${ }^{19}$ e antirracista a partir de indagações firmadas na resistência afroperspectivista " $O$ termo afroperspectivista tem um sentido simples, o conjunto de pontos de vista, estratégias, sistemas e modos de pensar e viver de matrizes africanas" (NOGUEIRA, 2012, p. 147), como maneira de representar os valores humanos em conveniência de um corpo social capaz de partilhar as vivências.

A metodologia aplicada foi fundada a partir de manifestações abrandadas com materiais equilibrados no afrocentrismo ${ }^{20}$, como leitura de textos, exibições de vídeos e imagens, onde

\footnotetext{
13 “Coletividade de indivíduos humanos com características somáticas semelhantes, que compartilham a mesma cultura e a mesma língua, além de identificarem-se como grupo distinto dos demais" (LOPES, 2011, p. 508).

${ }^{14}$ Para Kabengele Munanga (1996), professor da Universidade de São Paulo e africano radicado no Brasil, “a identidade passa pela cor da pele, pela cultura, ou pela produção cultural do negro; passa pela contribuição histórica do negro na sociedade brasileira, na construção da economia do país com seu sangue; passa pela recuperação de sua história africana, de sua visão de mundo, de sua religião".

${ }^{15}$ Nei Lopes (2011, p. 147) declara que é um "Sentimento de amor-próprio, dignidade; moral elevado; ânimo forte; disposição para enfrentar as adversidades da vida. A atuação dos movimentos negros em todo o mundo tem se dirigido para o fortalecimento da autoestima de africanos e de seus descendentes, seriamente abalada pela escravidão e pelo racismo".

${ }^{16}$ Qualitativo do indivíduo brasileiro de origem africana e de tudo que lhe diga respeito. Relativo, ao mesmo tempo, a África e ao Brasil, como o indivíduo brasileiro de ascendência africana. LOPES, Nei. "Dicionário escolar afro-brasileiro". São Paulo - Selo Negro Edições, 2006, p. 22.

17 "No Brasil, o vocábulo, que durante muitos anos foi sinônimo de "escravo", passou, com o tempo, a ser um termo étnico e político, usado como autodenominação até pelos afrodescendentes de pele clara" (LOPES, 2011, p. 922).

18 "No Brasil, antiga categorização etnorracial do mulato" (LOPES, 2011, p. 1006).

${ }^{19}$ A ativista e pesquisadora Catherine Walsh (2013) foi quem delimitou a referida abordagem por sugerir práticas insurgentes no processo de formação escolarizada, no entanto, também, em outros espaços de conhecimento. Onde se destaca a publicação "Pedagogias Decoloniais: práticas insurgentes de resistir, (re)existir y (re)vivir", livro organizado por ela no ano de 2013.

${ }^{20}$ Teoria filosófica que serve de base ao moderno afrocentrismo. Formulada pelo cientista social Molefi Kete Asante, ela não impõe um pensamento único, como faz o eurocentrismo, admitindo e exaltando, segundo Larkin
} 
auxiliaram a consumação de Rodas de Diálogos, Exposição de livros de literatura africana, indígena e afro-brasileira, Apresentação de Slides, Oficina de Escrevivências ${ }^{21}$, entre outras, como estratégias positivas, para assim, propor a descolonização dos olhares dos Alunos, que estavam a todo o tempo sustentados nos arquétipos eurocêntricos que estão radicados no ambiente escolar.

A partir destas dinâmicas sensibilizadoras, proporcionamos aos Alunos negros (as) a elevação da estima, o resgate da sua ancestralidade, história e cultura. Oportunizando também aos Alunos (as) de outras etnias, um conhecimento potente sobre as Histórias das Áfricas e a cultura povos africanos, as diversidades dos povos indígenas no Brasil, e as múltiplas formas de resistência da história, cultura e religiosidade dos afro-brasileiros, que foram influenciadas pelos Povos Bantu e a sua diáspora.

Desta forma, este artigo toca nas possibilidade de uma educação étnico-racial, para que possamos repensar em novas correntes hegemônicas presentes em nossa sociedade, principalmente nos currículos aplicados no Chão da Escola, que se enunciam na Disciplina de História, no confronto às lesões propiciadas pelas discriminações e os preconceitos sucedidos nos ambientes de educação, idealizando e construindo táticas sólidas para a colaboração da construção que reverenciam às identidades negras em conveniência à atenuação do racismo.

\section{A LEI, A EDUCAÇÃO E O RESGATE DA CULTURA}

Dentro dos apontamentos à anterior, podemos interpretar que ao trabalhar com as concepções das Leis Federais 10.639/2003 e 11.645/2008, é uma tarefa complexa de atuação, para a promoção de conhecimentos mais cortês, e antirracista no espaço de educação. As Leis nos possibilitam lutar por direitos e por uma história não eurocêntrica, que sempre esteve pautada na figura de grandes heróis brancos.

Mesmo que já tenha se passados extenuados 18 anos da sua publicação, ainda é necessário avultar a existência nos espaços de educação de feitio mais amplo, bem como entusiasmar

Nascimento (2009), o diálogo, com linhas de pensamento contrárias, "com respeito mútuo e sem pretensão à hegemonia" para saber mais (Lopes, 2011, p. 56).

${ }^{21} \mathrm{O}$ conceito de escrevivência vem sendo um caminho teórico discutido por críticos e estudiosos da literatura afrobrasileira. A intelectual Conceição Evaristo é referência obrigatória nesse processo de escrita sobre às histórias, vivências e pensamentos silenciados e as narrativas dos grupos excluídos. Sobre isso a autora afirma que: "a nossa escrevivência não pode ser lida como história de ninar os da casa-grande, e sim para incomodá-los em seus sonos injustos" (EVARISTO, 2007). Para saber mais consultar Conceição Evaristo "Da grafia-desenho de minha mãe um dos lugares de nascimento de minha escrita”. In: ALEXANDRE, Marcos Antônio. (Org.) Representações performáticas brasileiras: teorias, práticas e suas interfaces. Belo Horizonte: Mazza, 2007. p. 16-21. 
agentes e docentes para o seu cumprimento. No momento presente, as ações para a implementação da Lei 10.639/03, manteve-se centradas na figura dos profissionais simpatizantes as perspectivas das Leis.

Visto que, ainda encontramos nos espaços de educação, que tem em seu quimérico pedagógico, que o uso da implementação da Lei Federal 10.639/03, é uma atribuição cerceada apenas aos professores e professoras que se colocam publicamente, à uma postura voltada para às políticas pedagógicas voltadas para a diversidade ${ }^{22}$, ou mesmo, um assunto que deve ser desenvolvido na escola apenas por professores negros (as) engajados nas questões das relações étnico-raciais, ou também devido a quantidade de melanina ${ }^{23}$ existentes na pele dos mesmos (GOMES, 2010).

A propósito, a tempos vem havendo infinitos modos de interferências civis e governamentais com a intenção de avolumar as indagações compenetradas para a efetivação da Lei. Todavia, sucederam inúmeras obstruções que ainda colocam em perigo a evolução e elevação de sua permanência, como muitos pesquisadores apresentam em suas pesquisas sobre os entraves e avanços para o cumprimento do Artigo 26-A da LDBEN.

Contudo, para que esta Lei possa fazer parte de forma ativa e profícua na sociedade educacional e demais espaços, ainda existe alguns impedimentos para que possa encontrar as portas abertas, e assim motivar a abordagem das suas possibilidades fundamentais, que foram propostas na Lei em questão.

É considerável salientar, que estes impedimentos, vem sendo delatados por educadores, pesquisadores e também pelo Movimento Negro ${ }^{24}$ "Nome genérico dado, no Brasil, ao conjunto de entidades privadas integradas por afrodescendentes e empenhadas na luta pelos seus direitos de cidadania" (LOPES, 2011, p. 885) que assinalam impasses acerca da exiguidade de Cursos de Formação Pedagógica em relação as finalidades das Leis Federais 10.639/2003 e 11.645/2008, sem esquecer de mencionar a insuficiência de materiais, didáticos e paradidáticos que não estão presentes nas Salas de Aula, ocasionando à não subvencionar os Docentes e demais Colaboradores da área de educação.

\footnotetext{
${ }^{22}$ Nas palavras de Munis Sodré (2001) a diversidade étnico-cultural nos mostra que os sujeitos sociais, sendo históricos, são também, culturais. Essa constatação indica que é necessário repensar a nossa escola e os processos de formação docente, rompendo com as práticas seletivas, fragmentadas, corporativistas, sexistas e racistas ainda existentes.

${ }^{23}$ Pigmento responsável pela cor da epiderme, dos pelos e dos olhos de pessoas e animais. A concentração ou a dispersão desse pigmento nas células é que determina a cor mais escura ou mais clara dos grupos humanos (LOPES, 2011, p. 840).

${ }^{24}$ A respeito dos processos de mobilizações e organização do movimento negro no Brasil referidos ao século passado e atual, podemos nos portar em referenciais como: Roger Bastide, 1972; Florestan Fernandes, 1978; Clóvis Moura, 1983; Kabengele Munanga, 1996; Amauri Mendes Pereira, 2008; Antônio Liberac C. S. Pires; Amilcar Araújo Pereira, 2007; Sales Augusto dos Santos, 2005, entre outros.
} 
Desse forma, ela não será exposta e consagrada pelos Profissionais de Educação e demais Agentes, atrapalhando na integração os concernentes conteúdos que engloba a História e Cultura Africana, dos Afro-brasileiros e dos Grupos Indígenas nos currículos da Educação Básica.

Seguindo, no Estado do Rio de Janeiro e arrabaldes, durante os 18 anos, foram realizados uma sucessão de Cursos de Formação Continuada para Professores, e também à militantes do Movimento Negro e a sociedade civil, que se apoquentar com a formação de uma sociedade mais democrática e justa.

Não obstante, estas ações compensatórias de ampliações, supostamente não completa toda a falta de intervenções insufladas com estas asserções para cursos e oficinas pedagógicas para educadores.

O inconveniente é detectado no acesso aos materiais confeccionados, à promoção da existência desses materiais e por último, mais não menos importante, a inexistência de fomento e relevância de uma parcela de Educadores e Instituições de Ensino, que engatam à implementação das Leis Federais, meramente aos Educadores afro-brasileiros, como já mencionado à anterior.

Ou mesmo restringindo aos Professores que professam aulas da Disciplina de História "como área do conhecimento tem teorias e métodos próprios. Profissionais desse campo tem se voltado para a história da África e da população negra na diáspora” (BRASIL, 2006, p. 219), literatura, geografia ou artes, e em exclusivo, nas culminância sempre realizada nas últimas semanas do mês de novembro ${ }^{25}$, como simplesmente um cumprimento descomprometido sobre a História e a Cultura do Negro, como modo de execução da Lei 10.639/03.

Complementando a todas as escusas à precedente para a "não" implementação da Lei 10.639/03, esbarramos também em contratempo atribuído por uma quantidade significativa de Educadores e Agentes Educacionais, que se repudiam em trabalhar as discursões, que são atreladas a História e Culturas Africanas e Afro-brasileira.

Entretanto, a renitência nessa questão é a ausência de sensibilidade dos colegas, atrelada a antipatia em levar para dentro da Sala de Aula, argumentações pertinentes acerca de tais controvérsias, como por exemplo as perspectivas ligadas à cotas sociais e raciais, discriminação

\footnotetext{
${ }^{25}$ No mês de novembro, alguns municípios brasileiros transformaram este mês em "Mês da Consciência Negra", onde ocorrem constantes eventos sensibilizadores para a amenização do racismo, promovido por órgãos do governo, Movimento Negro e pelas instituições de ensino.
}

\begin{tabular}{l|l} 
v. 5 & n. 2 \\
\hline
\end{tabular}


étnico-raciais ${ }^{26}$, preconceito, colorismo ${ }^{27}$, estética "Pensar sobre experiências estéticas perpassa por uma reflexão acerca do corpo e tudo aquilo que o atravessa e o toca" (OLIVEIRA e FERNANDES, 2019, p. 129), religiosidades de matriz africana, identidade, racismo, ações afirmativa, racismo religioso, branquitude ${ }^{28}$ entre outras perspectivas que perpassam, apropriado ao sentimento de inaptidão dos Profissionais Educacionais em referência ao domínio das temáticas, ou mesmo a indisposição em fomentar ponderações descolonizadoras sobre os grupos africanos e a sua diáspora no Brasil.

A frente das reflexões apresentadas, o presente trabalho planeja ocasionar e oportunizar nos Estimuladores Educacionais, uma ação compenetrada em relação à circunstância de se consolidar caminhos possíveis que proporcione de modo efetivo a implementação do Artigo 26 A da LDBEN, desejando minguar os mecanismos constituídos pelo racismo, pela discriminação e pelo preconceito, que vemos de modo mascarado nos Espaços de Educação.

Vale destacar que o "Educandário Carolina Maria de Jesus" tinha em seu quadro de Profissionais de Educação, apenas Eu e mais uma Professora Negra, no qual havia uma grande dificuldade de se ver como tal, Gomes (2003, p. 171) destaca que "Construir uma identidade negra positiva em uma sociedade que historicamente, ensina ao negro, desde muito cedo, que para ser aceito é preciso negar-se a si mesmo, é um desafio enfrentado pelos negros brasileiros".

A Escola utilizava práticas cotidianas inspiradas no racismo estrutural "é o racismo que extrapola as relações interpessoais e ocorre à revelia das boas intenções individuais, implicando o comprometimento dos resultados de planos e metas de instituições, gestões administrativas e de governo" (ARAÚJO, TOLENTINO e SILVA, 2018, p. 256) e também no racismo institucional ${ }^{29}$. Onde foi possível observar por diversas vezes, piadinhas e fundamentações racistas, praticadas por Professores e Coordenadores Pedagógicos para com os seus Alunos

\footnotetext{
26 “Toda distinção, exclusão, restrição ou preferência baseada em raça, cor, descendência ou origem nacional ou étnica que tenha por objeto anular ou restringir o reconhecimento, gozo ou exercício, em igualdade de condições, de direitos humanos e liberdades fundamentais nos campos político, econômico, social, cultural ou em qualquer outro campo da vida pública ou privada" (COELHO, 2018, p. 123).

${ }^{27}$ Segundo Oliveira e Fernandes, afirmam que "O colorismo, termo criado por Alice Walker em 1982, [...] o colorismo considera e prevê hierarquias as variadas tonalidades de pele [...] e consequentemente, atribuindo aos indivíduos de pele mais escura o menor valor (OLIVEIRA e FERNANDES, 2019, p. 135).

${ }^{28}$ De acordo com Bento, a branquitude pode ser definida como "traços da identidade racial do branco brasileiro a partir das ideias sobre branqueamento" (BENTO, 2002, p. 29).

${ }_{29}$ Andrea Maila Voss Kominek e Ana Crhistina Vanali afirma que é "Quando normas ou práticas estatais, aparentemente neutras, têm efeitos injustificáveis e desproporcionais para grupos racialmente vulneráveis da sociedade, seja no âmbito público, estatal ou privado. Normas e práticas neutras em propósito, mas com efeitos prejudiciais e excludentes a grupos específicos" (Kominek e Vanali, 2018, p. 89).
} 
Negros e Pardos, utilizando também em pleno século XXI às perspectivas do Mito da Democracia Racial ${ }^{30}$.

Os currículos da instituição, eram trabalhados com perspectivas conteúdistas aos moldes eurocêntricos e etnocêntricos ${ }^{31}$, distorcidos por equívocos e preconceitos salvando apenas os dias 19 de Abril $^{32}, 13$ de Maio $^{33}$ e 20 de Novembro ${ }^{34}$. Desse modo, invisibilizava as Histórias e Culturas Africanas, dos Grupo Indígenas e Afro-brasileira em seus currículos, e consequentemente a potência dos Alunos Negros neste espaço de saber.

Poucos Alunos tinha o entendimento sobre as tensões geradas pelo racismo, embora os mesmos, fossem filhos de pessoas influentes no país, jogadores de futebol, artistas, cantores, empresários e outros. Todos os episódios sérios de racismo, "não" eram articulados e resolvidos com as respectivas turmas, como forma de amenizar os impactos e as propagações racistas, pelo contrário, todos os problemas levados para a Coordenação do "Educandário Carolina Maria de Jesus", era transformado em apenas uma "brincadeirinha" ou Bullying ${ }^{35}$, no entanto na maioria das vezes, advertiam os Alunos agredidos pelas ações racistas e os transformavam em verdadeiros vilões dramáticos, reproduzindo assim, práticas amparadas no Racismo velado.

\section{A OFICINA DECOLONIAL NO CHÃO DA ESCOLA}

\footnotetext{
${ }^{30}$ Nas palavras de Ronilda Iyakemi Ribeiro, (1998, p. 64), “no Brasil, último país a abolir a escravidão e primeiro a declarar-se país de democracia racial, este mito associado à força da ideologia do branqueamento tecem o pano de fundo das relações raciais. A extinção da escravidão sem projeto de inserção social, impingiu aos afrodescendentes a condição de sub-cidadania e a responsabilidade pelo fracasso passou a ser atribuída a uma suposta incompetência individual e não à conjuntura socioeconômica-política”.

${ }^{31}$ Que vem de etnocentrismo: maneira típica de ver o mundo de quem considera seu grupo étnico, nação ou nacionadildade mais importante do que as demais.

${ }^{32}$ No dia 19 de abril é tido como o "Dia Nacional do Índio". Atualmente, os grupos indígenas tentam transformar em "Dia da Conscientização para a Questão Indígena", como forma de defesa da sua cultura e dos direitos de seus povos.

${ }^{33}$ Durante muito tempo, as questões do negro no Brasil, só eram lembrado de forma educativa ou comemoração cívica, somente na data do 13 de maio, dia da assinatura da Lei Áurea, em 1888, onde declarou extinta a escravidão no Brasil. Esta data era conhecida como o "Dia da Libertação dos Escravos" sem se discutir as lutas e resistências dos grupos negros para a sua própria libertação. O Movimento Negro tem interpretado esta data como "Dia Nacional de Luta contra o Racismo", de modo à reeducar e contruir novos saberes e diálogos.

${ }^{34}$ No Estado do Rio de Janeiro, é decretado como feriado o dia 20 de novembro, data da morte do líder quilombola Zumbi dos Palmares, estabelecido com o "Dia da Consciência Negra” sancionada pela Governadora Benedita da Silva pela LEI No 4007, DE NOVEMBRO DE 2002.

35 Beaudoin e Taylor afirmam que "Compreende todas as formas de atitudes agressivas, realizadas de forma voluntária e repetitiva, que ocorre, sem motivação evidente, adotadas por um ou mais estudantes contra outro(s), causando dor e angustia e realizada dentro de uma relação desigual de poder" (BEAUDOIN e TAYLOR, 2006).
} 
Com a motivação em contribuir com as ações afirmativas, em conservar as lutas e realizações granjeado pelo Movimento Negro, como forma de resistência e dedicação, na busca do enfraquecimento dos artifícios do racismo, que ainda persiste de forma penetrada e estabelecendo hierarquias entre os grupos étnicos que se configuram nesta sociedade. Assim, surge a ideia de criar a Oficina Pedagógica intitulada "Os Povos Bantu e suas Contribuições Decoloniais no Chão da Escola" como uma maneira de preservar e promover a igualdade racial e a moderação do racismo.

Esta oficina foi desenvolvida a partir de inspirações escoradas na implementação da Lei Federal 10.639/03 e 11.645/08, na resistência de uma educação étnico-racial, na interdisciplinaridade para valorizar a ancestralidade africana "é o que estrutura a cosmo-concepção de mundo das culturas africanas, é a fonte dos elementos fundamentais da tradição africana. Ancestralidade é a tradição, pertencimento que perpassam as experiências africanas e afrodescendentes perpassados pela diáspora" (MACHADO e OLIVEIRA, 2018, p. 69) negra, com desígnios na trajetória e conjuntura atual do afro-brasileiro. Ambicionando, que todos os participantes "negros" e os "não negros" presentes na atividade, se notassem, como parte importante desta ação afirmativa, para o progresso do respeito e o amor-próprio dos afrodescendentes, em prol de uma educação étnico-racial.

Devido as negativas à anterior, durante todo o ano, conseguimos trabalhar de modo solitário, do seguinte modo, em uma semana seguindo os conteúdos curriculares da Disciplina de História de forma categórica, mais ainda amparado nas Leis Federais 10.639/03 e 11.645/08 e na semana seguinte, trabalhando com as turmas do $6^{\circ}$ Ano do Ensino Fundamental com a Oficina interdisciplinar intitulada "Os Povos Bantu e suas Contribuições Decoloniais no Chão da Escola”.

Vale ressaltar, que o "Educandário Carolina Maria de Jesus" criou alguns entraves para o sucesso das oficinas, no entanto é mais relevante relatarmos sobres as potencias das atividades na luta antirracista.

Todos os dias, que as aulas da Disciplina de História, coincidiam com o dia da nossa Oficina, a nossa sala era ornamentada com objetos e tecidos étnicos, bonecas negras, bonecos de super heróis negros e livros de Literatura Africana, Indígena e Afro-brasileira. Onde realizávamos a Exposição do "Projeto de Sensibilização Étnico-Racial e Cultura Africana na Sala de Aula" com os livros que trabalhavam com as temáticas que articulavam e/ou colocava em pauta questões relacionadas aos Povos Bantu, racismo, identidade negra, auto-estima e cultura afrobrasileira. Meu avô africano (CAMPOS, 2010), Foi vovó que disse (MUNDURUKU, 2015) e O mundo no black power de Tayó (OLIVEIRA, 2013) entre outros. 
Sempre antes de iniciar as Oficinas, inspirado nas tradições Griôn ${ }^{36}$ e na tradição Oral “A tradição oral é repensada como forma de gritar a própria alteridade" (RUI, 1985), onde contavase sempre uma história sobre as Histórias das Áfricas, dos Povos Indígenas e dos Afrobrasileiros.

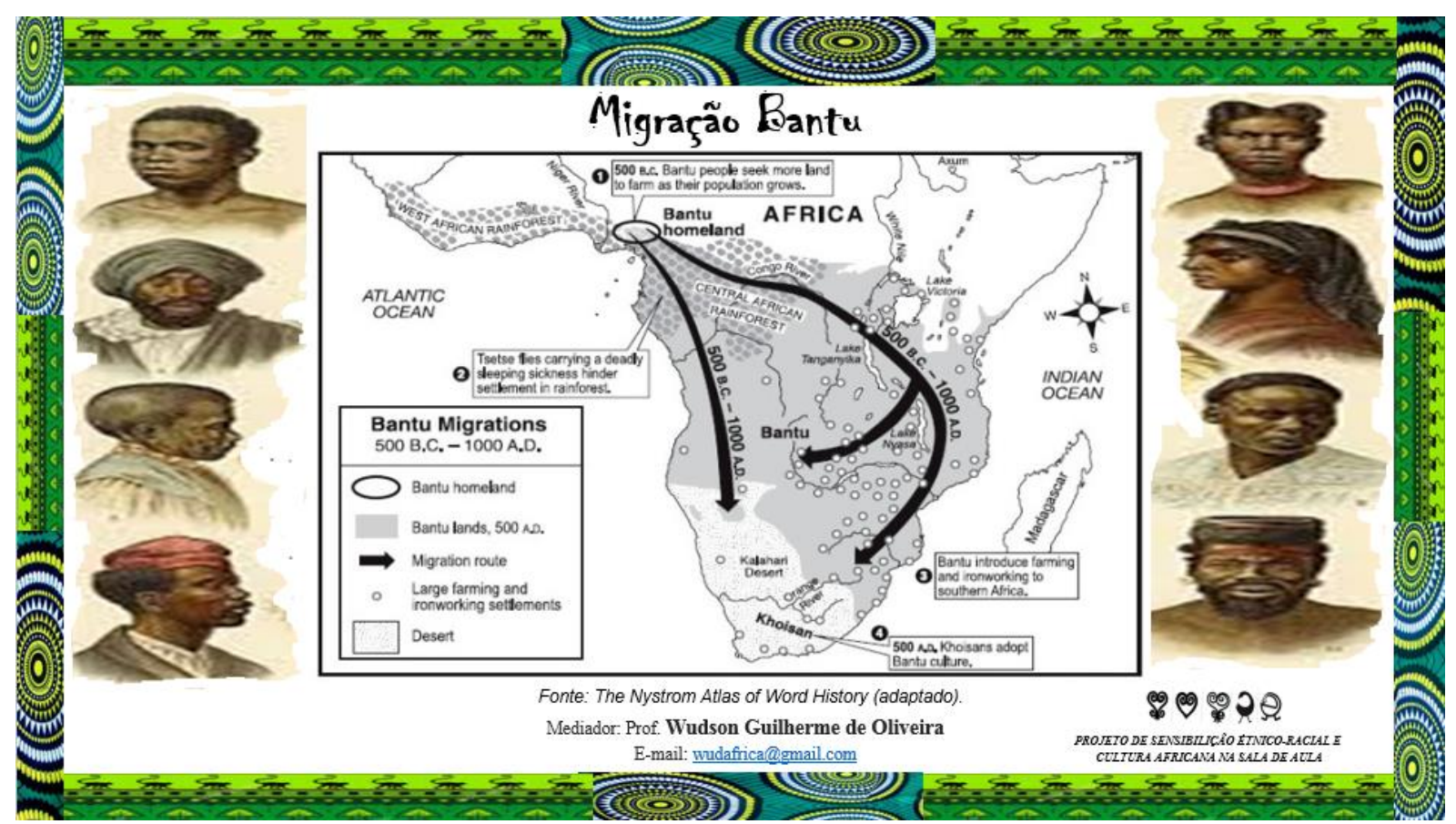

Figura 1. Slide sobre a Migração Bantu.

Fonte: The Nystrom Atlas of Word History.

Arte: Wudson Guilherme (professor).

Todos os dias das execuções da Oficina, foram distribuídos textos para subsidiar um conhecimento igualitário à todos os Alunos, independente da sua ancestralidade étnica. E através da utilização do DataShow, apresentamos Slides com o mapa do Continente Africano, e a diversidade étnica e cultural encontrado neste vasto continente. Após, apresentamos para os Alunos os territórios do Continente Africano, onde se iniciou o tronco linguístico Bantu e suas características históricas, culturais e étnicas.

No que se refere aos Povos Bantu, podemos ter variados entendimentos entre eles, uma grande proporção dos habitantes da terça parte meridional do continente africano. Além disso também,

\footnotetext{
${ }^{36}$ Nei Lopes explica que é um "Termo criado na época colonial para designar o narrador, cantor, cronista e genealogista que, pela tradição oral, transmite a história de personagens e famílias importantes das quais, em geral, está a serviço. Presente sobretudo na África ocidental, notadamente onde se desenvolveram os faustosos impérios medievais africanos (Gana, Mali, Songai etc.), recebe denominações variadas: dyéli ou diali, entre os bambaras e mandingas; guésséré, entre os saracolês; wambabé, entre os peúles; aouloubé, entre os tucolores; e guéwel (do árabe qawwal), entre os uolofes (LOPES, 2011, p. 596 e 597).
} 
é um "grande conjunto de povos africanos disseminados do centro para o leste, sul e sudeste do continente. Falantes de línguas semelhantes no Congo, em Angola, na Tanzânia, em Moçambique, na África do Sul” (LOPES, 2008).

De fato o "Bantu" também é entendido como um tronco linguístico que se iniciou com os bantufonos, conforme Bruna Marques e Renato Nogueira (2013) demonstram:

Bantufonos diz respeito ao conjunto de povos falantes, isto é, a ênfase está nas línguas que mais de 400 povos falam, neste caso usamos o termo bantu como plural ou estrutura linguística basilar que associada ao termo fonos designa bantufonos, conjunto de povos falantes de idioma bantu. Banto se refere a um povo específico, ênfase no aspecto cultural. Por exemplo, na frase: "esse costume de cuidar das crianças numa família extensa que envolve avós e tias é banto". Ora podemos perceber isso entre no povo Herero que vive no sul de Angola e norte da Namíbia e na região norte da África do Sul entre os zulus. O povo Herero e o povo Zulu têm culturas próprias e específicas; mas, são, em termos afrocentrados, culturalmente de raiz banto (MARQUES e NOGUERA, 2013).

A partir de tais fundamentos, podemos observar que o Bantu é na verdade, bem mais que um grupo étnico estabelecido, este conjunto de línguas aparentadas, aglutinam múltiplos conjuntos de pessoas, que compartilham um mesmo tronco linguístico trivial, onde abraçam mais de quatrocentas variações plurais, vindas de um mesmo antepassado, intitulada como protobanta "O protobanto era falado em uma região fronteiriça no plano ecológico, dispondo portanto de um meio assaz rico, conquanto pudessem dele usufruir os seus habitantes" (LWANGALUNYIIGO e VANSINA, 2010, p 182). Dando continuidade à análise, sobre as observações da palavra "Bantu", acrescenta-se também a um conjunto de povos que são encontrados historicamente em um extenso território localizado na África Central, onde geograficamente se originou na Nigéria e posteriormente se estendeu para outras áreas de modo diásporico, para determinados países localizados no Continente Africano. 


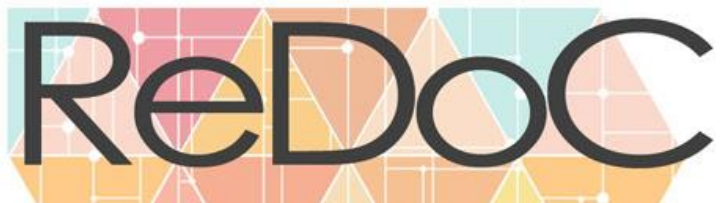

\section{Revista Docência e Cibercultura}

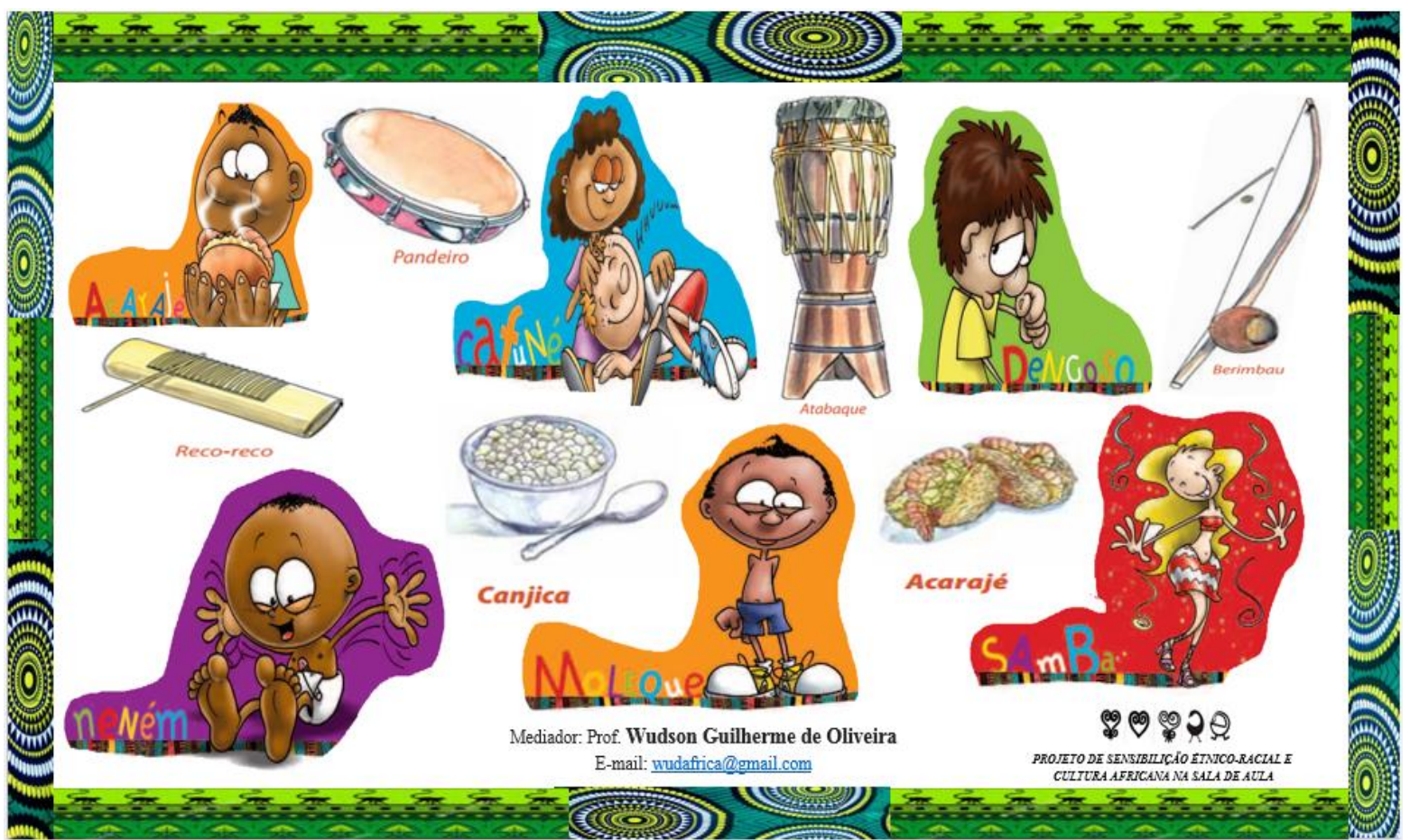

Figura 2. Slide sobre algumas palavras do tronco linguístico Bantu.

Fonte e Arte: Wudson Guilherme (professor).

Podemos afirmar entre os séculos XVI e XIX, milhões de corpos africanos vindos dos territórios Bantu, atravessaram o Atlântico de forma forçada amontoados nos tumbeiros, sem objetos pessoais e tendo como destino os portos brasileiros. Porém, esses grupos que foram obrigados a fazerem estas migrações, foram subjugados e transformados em mãos-de-obra escravas especializadas.

Porém, esses grupos subjugados e transformados em mãos-de-obra escravas especializadas, trouxeram consigo, infinitas bagagens intelectuais e culturais, entre elas as suas estruturas linguísticas Bantu e as referências históricas, que resistiram aos impactos e as dificuldades encontradas na sociedade colonial escravocrata portuguesa.

No território brasileiro, existe uma grande predominância da contribuição vocabular dos grupos diásporico falantes das línguas Bantu, notadamente o umbundo, o quimbundo e o quicongo.

Por acaso, são desses idiomas originários do Continente Africano, que provavelmente eternizaram as palavras de tronco linguístico denominado Bantu, onde a maioria dessas palavras são utilizadas em nosso dia a dia como, por exemplo: acarajé ${ }^{37}$, axé $e^{38}$, angu, bengala,

\footnotetext{
${ }^{37}$ Bolinho de feijão frito no dendê e servido com camarões secos.

${ }^{38}$ É a força vital que unifica espiritualmente as comunidades de candomblé.
}

v. 5 n. 2

p. 308 
Baobá $^{39}$, bugiganga, búzios, cuíca, cafuné, cachaça, dendê, dengue, Erêe ${ }^{40}$, Exú ${ }^{41}$, fofoca, fuzuê, ginga, gororoba, hã, Haúças, Iemanjá, jiló, jongo ${ }^{42}$, lundu, moleque, muamba ${ }^{43}$, mulungo, mochila, nanar, nenê, odara, Orixá ${ }^{44}$, Oxalá, ori, perrengue, pirão, pururuca, quitanda, quiabo, ranzinza, reco-reco, sacana, sunga, sopapo, samba ${ }^{45}$, trambiqueiro, toco, titica, ué, umbanda, urucubaca, vatapá, xingar, xodó, zangado, Zumbi ${ }^{46}$ e milhares de outras palavras que influenciaram de modo positivo na influência da língua portuguesa falada no Brasil.

\section{SABEDORIAS DOS POVOS BANTU SALIENTADOS}

A ação afirmativa e pedagógica teve como temática central, apresentar os grupos Bantu aos Alunos, como conteúdo curricular da Disciplina de História, onde foi possível: Contextualizar a riqueza cultural, histórica e linguística que foram deixadas como legado e resistência para a nossa sociedade; Analisar algumas palavras de origem africana Bantu que permeiam em nossos meios sociais, que foram incorporadas a língua portuguesa a partir do período escravocrata, sobrevivendo a higienização e persistindo aos dias atuais.

A atividade esteve repleta de sensibilizações contundentes para a implementação do Artigo 26 A da LDBEN, para a promoção de uma educação étnico-racial. Ao longo da atividade, buscamos a partir de laminas de slides, vídeos, imagens e livros para tocar nas perspectivas da Lei Federal 10.639/03, que serviram como estratégias para romper as barreiras do racismo "remete a um conjunto de teorias, crenças e práticas que estabelece uma hierarquia entre as raças, consideradas como fenômenos biológicos" (MUNANGA, 2004) em prol do respeito e a diversidade ${ }^{47}$ e a igualdade, a partir de práticas e ações educativas, a fim de dialogar e promover

\footnotetext{
39 Árvore de tronco enorme, reverenciada por seus poderes mágicos.

${ }^{40}$ Divindade ligada à infância. Criança, em iorubá.

${ }^{41}$ Divindade que é considerada o intermediário entre o Orum (céu) e o Aiyê (terra). Aquele que está em todos os lugares. Dono das encruzilhadas.

${ }^{42}$ Dança de umbigada na qual homens e mulheres sapateiam, alternadamente, ao centro de uma roda, provocandose um ao outro, ao ritmo dos tambores e de cantos de desafio.

${ }^{43}$ Cesto para carregar mercadorias. Contrabando.

${ }^{44}$ Nome genérico das divindades yoruba, intermediários entre Oloru, o Deus Supremo, e os seres humanos. Ocupam posição central na cultura yoruba e sobrevivem na América, no Caribe, na América do Sul com suas variadas designações.

${ }^{45}$ Do "semba", dança de umbigada ou de peitada praticada em algumas regiões da África.

${ }^{46}$ Espírito que vagueia entre as sombras. Último líder do Quilombo dos Palmares. No dia 20 de novembro, data de sua morte, comemora-se o Dia Nacional da Consciência Negra.

${ }^{47}$ Nas palavras de Munis Sodré (2001) a diversidade étnico-cultural nos mostra que os sujeitos sociais, sendo históricos, são também, culturais. Essa constatação indica que é necessário repensar a nossa escola e os processos de formação docente, rompendo com as práticas seletivas, fragmentadas, corporativistas, sexistas e racistas ainda existentes.
} 


\title{
Revista Docência e Cibercultura
}

a História dos Povos Africanos, Grupos Indígenas e a Cultura Afro-brasileira na construção história e cultura negra no país.

Isso se imprime nas palavras de Nilma Lino Gomes (2003) com a seguinte afirmação:

\begin{abstract}
Refletir sobre a cultura negra é considerar as lógicas simbólicas construídas ao longo da história por um grupo sociocultural específico: os descendentes de africanos escravizados no Brasil. Se partirmos do pressuposto de que o nosso país, hoje, é uma nação miscigenada, diríamos que a maioria da sociedade brasileira se encaixa nesse perfil, ou seja, uma grande parte dos brasileiros pode se considerar descendente de africanos (GOMES, 2003, p. 78).
\end{abstract}

Sendo assim, mesmo o Brasil sendo um território extenso e de múltipla diversidade étnica e cultural, atualmente ainda encontramos barreiras atreladas ao conservadorismo da sociedade, a falta de reflexões sobre as questões raciais nas esferas relacionadas a educação, onde "contribui para que as diferenças de fenótipos entre negros e brancos sejam entendidas com desigualdades naturais" (BRASIL, 2009) devido ao "não" lançamento de um olhar mais sensibilizado amparado na afrocentricidade 48 "é uma posição intelectual, uma perspectiva política, um paradigma que toma a África como referência para autodefinição assertiva de si mesma e dos povos africanos no continente e fora dele" (MARQUES e NOGUERA, 2013), que promova a reflexão e o respeito no ambiente educacional integrando relações mais igualitárias, sintonia com as exigências das Leis Federais 10.639/03 e 11.645/08 do Artigo 26 A da LDBEN na inserção da temática racial e a pluralidade étnico-racial brasileira nos currículos escolares.

\footnotetext{
${ }^{48}$ Para saber mais sobre Afrocentricidade, buscar Molefi Asante "Afrocentricidade: notas sobre uma posição disciplinar" In NASCIMENTO, Elisa Larkin. Afrocentricidade: uma abordagem epistemológica inovadora. Tradução Carlos Alberto Medeiros. São Paulo: Selo Negro, 2009, p. 93-110.
}

\begin{tabular}{l|l} 
v. 5 & n. 2
\end{tabular}




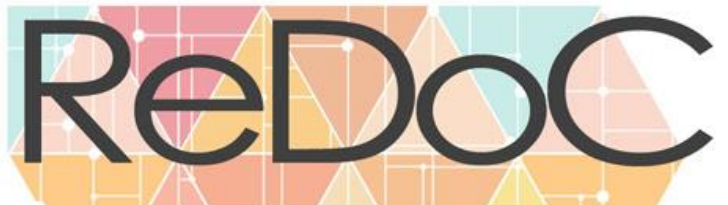

\section{Revista Docência e Cibercultura}



Figura 3. Exposição de Livros e participação dos alunos nas atividades.

Fonte e Arte: Wudson Guilherme (professor).

Em todo o tempo, houve a possibilidade de se aproximar a realidade social e étnica dos participantes, facilitadas a partir dos recursos de estratégias áudios visuais, bibliográficas entre outros, bem como as inspirações dos conceitos ancorados nos Valores Civilizatórios Afrobrasileiros $^{49}$, corroborando em sintonia com a ludicidade e com a oralidade ${ }^{50}$, entre outros aspectos para a construção de um pertencimento étnico-racial em relação as culturas que permeiam todas as extensões sociais do Brasil.

Durante a realização das atividades foram distribuídos copias de textos e um dicionário com algumas palavras Bantu, com o intuito de discutir, analisar e pensar a partir das leituras, questões plausíveis para a superação do preconceitos e do racismo existente em nosso cotidiano, com a intenção de subsidiar discursões mais fundamentadas em prol de um diálogo reflexivo para promover o resgate da identidade negra a partir da cultura Bantu.

\footnotetext{
${ }^{49}$ No Brasil existem valores originários da matriz africana que constituem elementos fundadores de nossa cultura: solidariedade, sociabilidade, hospitalidade, gestualidade, musicalidade. CUTI. Moreninho, neguinho pretinho. Coleção percepções da diferença negros e brancos na escola - Volume 3 - Brasília: Editora Nove\&Dez Criação e Arte, 2007, p. 49.

${ }^{50}$ Nas palavras de Petronilha Beatriz Gonçalves Silva "Plano de transmissão dos saberes em várias sociedades, aparentemente posto em segundo plano na modernidade. Além disso, considera-se que a oralidade é o meio de transmissão de conhecimento de grupos e coletividades tradicionais, em particular, aquelas que não registram seus fenômenos através da escrita" (SILVA, 2003, p. 188).
} 
Os Alunos produziram desenhos, música, histórias e escrevivências inspiradas nas perspectivas das contribuições deixadas pela influência das palavras da língua Bantu.

Realizamos também durante as Oficinas, Exposições de livros de literatura africana, indígena e afro-brasileira, que faziam parte do "Projeto de Sensibilização Étnico-Racial e Cultura Africana na Sala de Aula", com o objetivo de possibilitar os Alunos um maior contato com estes materiais e contribuir assim com a cidadania para uma sociedade mais justa, possibilitando aos participantes, um maior contato entre os Alunos na troca de saberes.

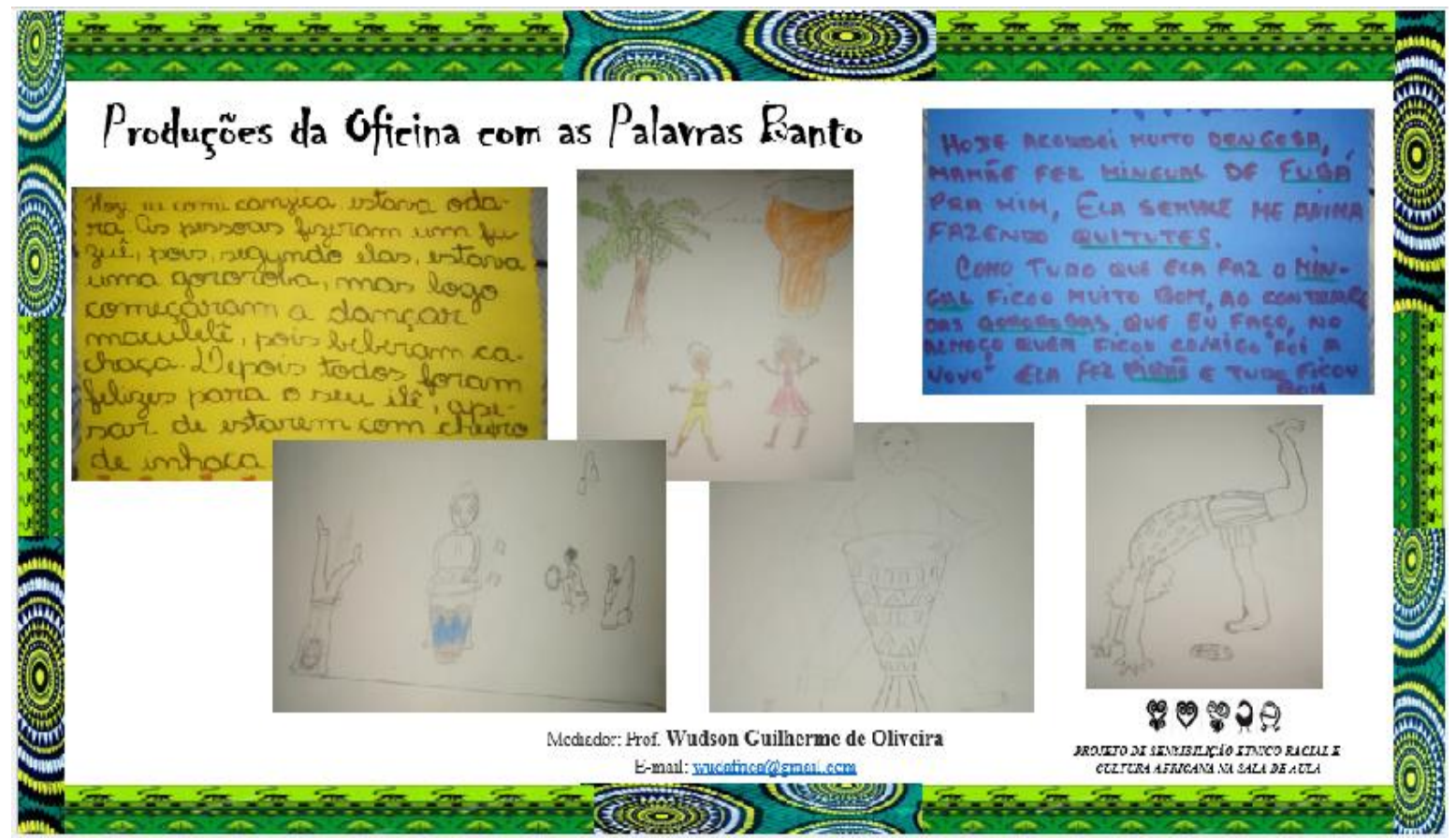

Figura 4. Produções dos Alunos, criadas durante a Oficina utilizando as Palavras Bantu. Fonte e Arte: Wudson Guilherme (professor).

A atividade foi uma experiência inovadora para muitos dos participantes, onde desmistificaram questões racistas e estereotipadas ${ }^{51}$, tidas como verdades absolutas por alguns, em relação a História e Cultura dos Africanos, dos Grupos Indígenas e dos Afro-brasileiros. Durante a realização da atividade, percebemos no decorrer da ação afirmativas, que grande parte dos participantes estavam muito interessados em conhecer um pouco mais sobre as questões relacionadas a diversidade cultural dos Bantu.

\footnotetext{
${ }^{51}$ Segundo Antonio Olímpio Sant'Ana, visões estereotipadas são opinião preconcebida, difundida entre os elementos de uma coletividade; conceito muito próximo de preconceito. "Uma tendência à padronização, com a eliminação das qualidades individuais e das diferenças, com a ausência total do espírito crítico nas opiniões sustentadas" (2004, p.57).
} 


\section{CONSIDERAÇÕES}

Defronte de todas as questões apresentadas neste texto, tentamos apresentar as múltiplas possibilidade em implementar as perspectivas do Artigo 26- A da LDBEN no Chão da Escola, nas aulas da Disciplina de História na turma do $6^{\circ}$ Ano do Ensino Fundamental. Onde percebemos sem sombras de dúvidas, a importância do protagonismo das línguas Bantu a partir do influxo civilizatório, que moldaram em nossa sociedade e história à partir da cultura africana presente no Brasil, bem como a importância deste tronco linguístico para a implementação das Leis Federais 10.6339/03 e 11.645/08, para a luta a favor de uma educação étnico-raciais.

Finalizamos que a atividade desenvolvida neste trabalho, cumpriu a função de colocar em prática as discursões sobre as intenções do Artigo 26 A da LDBEN, evidenciamos as luta dos Movimentos Negros e as medidas de ações afirmativas conquistadas graças as suas lutas em prol de dias melhores.

A educação é o principal elo que pode fazer ser propagada e disseminada as intensões das Leis Federais 10.639/03 e 11.645/08, valorizando assim as histórias e os feitos dos grupos africanos que aportaram no Brasil, dos seus descendentes afros-brasileiros e os indígenas em nossa sociedade, contribuindo de forma positiva no processo de eliminação das discriminações, a redução do racismo e a exclusão das desigualdades nos espaços formais e informais de educação.

\section{REFERÊNCIAS BIBLIOGRAFIA:}

ARAÚJO, Edna Maria de. TOLENTINO, Adivânia Nogueira. SILVA, Ananda Catharina Azevedo. Saúde da População Negra: Política Nacional de Saúde, avaliações e reflexões sobre suas diretrizes. In: KOMINEK, Andrea Maila Voss; VANALI, Ana Crhistina (Orgs.) Roteiros temáticos da diáspora: caminhos para o enfrentamento ao racismo no Brasil [recurso eletrônico] / Andrea Maila Voss Kominek; Ana Crhistina Vanali (Orgs.) - Porto Alegre, RS: Editora Fi, 2018, p. 243-264.

BRASIL. Orientações e Ações para Educação das Relações Étnico-Raciais. - Brasília: SECAD, 2006, p. 219.

BRASIL. Parecer do Conselho Nacional de Educação/Conselho Pleno/DF n. 3, de 2004 (Relatora Petronilha Beatriz Gonçalves e Silva). 
BRASIL. Resolução N. 1, de 17 de junho de 2004, do CNE/MEC, que "institui Diretrizes Curriculares Nacionais para a Educação das Relações Étnico-Raciais e para o Ensino de História e Cultura Afro- Brasileira e Africana".

BRASIL. Plano Nacional de Implementação das Diretrizes Curriculares Nacionais para a Educação das Relações Étnico-raciais e para o Ensino de História e Cultura Afrobrasileira e Africana, 2009.

BEAUDOIN, Marie-Nathalie e TAYLOR, Maurreen. Bullying e Desrespeito: como acabar com essa cultura na escola. Porto Alegre: Artmed, 2006.

BENTO, Maria Aparecida Silva. Branqueamento e branquitude no Brasil. In: CARONE, Iray e BENTO, Maria Aparecida Silva (orgs). Psicologia social do racismo: estudos sobre branquitude e branqueamento no Brasil. RJ: Vozes, 2002, p. 25-58.

CAMPOS, Carmem Lucia. Meu avô africano. São Paulo: Guia dos Curiosos Comunicações, 2010.

CARNEIRO, Sueli. A Construção do Outro Como Não-Ser Como Fundamento do Ser.

Tese de Doutorado em Educação, Universidade de São Paulo, 2005, p. 301.

CARREIRA, Denise e SOUZA, Ana Lúcia Silva. Indicadores da qualidade na educação: Relações raciais na escola / Ação Educativa, Unicef, SEPPIR, MEC - São Paulo: Ação Educativa, 2013, p. 45.

COELHO, André Luiz Querino. Racismo e Legislação no Brasil: perspectivas jurídicas. In: KOMINEK, Andrea Maila Voss; VANALI, Ana Crhistina (Orgs.) Roteiros temáticos da diáspora: caminhos para o enfrentamento ao racismo no Brasil [recurso eletrônico] / Andrea Maila Voss Kominek; Ana Crhistina Vanali (Orgs.) - Porto Alegre, RS: Editora Fi, 2018, p. 467-499.

CUTI. Moreninho, neguinho pretinho. Coleção percepções da diferença negros e brancos na escola - Volume 3 - Brasília: Editora Nove\&Dez Criação e Arte, 2007, p. 49.

EVARISTO, Conceição. Da grafia-desenho de minha mãe um dos lugares de nascimento de minha escrita. In: ALEXANDRE, Marcos Antônio. (Org.) Representações performáticas brasileiras: teorias, práticas e suas interfaces. Belo Horizonte: Mazza, 2007. p. 16-21.

GOMES, Nilma Lino. Educação, identidade negra e formação de professores/as: um olhar sobre o corpo negro e o cabelo crespo - Educação e Pesquisa, São Paulo, Volume 29, n. 1 jan/fev. 2003.

GOMES, Nilma Lino. Um olhar além da fronteira: educação e relações raciais. Belo Horizonte: Autêntica, 2010, p. 97 - 110. 
JESUS, Maria Carolina de. Onde estaes felicidade? In: DINHA. FERNANDEZ, Raffaella (org.) - São Paulo: Me Parió Revolução, 2014.

KOMINEK, Andrea Maila Voss. VANALI, Ana Crhistina. Presença Africana no Brasil: Desafios contemporâneos. In: KOMINEK, Andrea Maila Voss; VANALI, Ana Crhistina (Orgs.) Roteiros temáticos da diáspora: caminhos para o enfrentamento ao racismo no Brasil [recurso eletrônico] / Andrea Maila Voss Kominek; Ana Crhistina Vanali (Orgs.) - Porto Alegre, RS: Editora Fi, 2018, p. 77-92.

LOPES, Nei. Dicionário escolar afro-brasileiro. São Paulo - Selo Negro Edições, 2006, p. 22.

LOPES, Nei. Enciclopédia brasileira da diáspora africana / Nei Lopes. - 4. ed. - São Paulo: Selo Negro, 2011.

LOPES, Nei. História e cultura africana e afro-brasileira / Nei Lopes. - Barsa Planeta, 2008, p. 31, 67 e 90.

LWANGA-LUNYIIGO, Samwiri \& VANSINA, Jan. "Os povos falantes de banto e a sua expansão" In: História Geral da África, Volume III: África do século VII ao X. Brasília: UNESCO, Secad/MEC, UFSCar, 2010, p 182.

MACHADO, Adilbênia Freire. OLIVEIRA, Eduardo. Africanidades, Legislação e Ensino: Educação para relações étnico-raciais, lei 10.639, filosofia e ancestralidade. In:

KOMINEK, Andrea Maila Voss; VANALI, Ana Crhistina (Orgs.) Roteiros temáticos da diáspora: caminhos para o enfrentamento ao racismo no Brasil [recurso eletrônico] / Andrea Maila Voss Kominek; Ana Crhistina Vanali (Orgs.) - Porto Alegre, RS: Editora Fi, 2018, p. 49-76.

MARQUES, Bruna. NOGUERA, Renato. Um olhar afro-centrado sobre os bantos: o perfil étnico dos aportados no Rio de Janeiro (1790-1800). In: BERINO, Aristóteles. (org.) Diversidade Étnico-Raciais e Educação Brasileira - Seropédica, UFRRJ: Evangraf, 2013, p. 147-169.

MUNANGA, Kabengele. As facetas de um racismo silenciado. In Schwarcz, L M. \& QUEIROZ, R. Silva (orgs.) Raça e Diversidade. São Paulo: Estação Ciência: Edusp, 1996.

MUNANGA, Kabengele. Uma abordagem conceitual das noções de raça, racismo, identidade e etnia. In: BRANDÃO, André Augusto P. (Org.) Niterói: UFF. Cadernos 3, 2004, p. 15-35.

MUNDURUKU, Daniel. Foi vovó que disse. Porto Alegre: Edelbra, 2015. 
NOGUERA, Renato. Ubuntu como modo de existir: Elementos gerais para uma ética afroperspectivista. Revista da ABPN. v. 3, n. 6. nov. 2011 - fev. 2012, p. 147-150.

OLIVEIRA, Kiusam de. O mundo no black power de Tayó. São Paulo: Peirópolis, 2013.

OLIVEIRA, Wudson Guilherme de. FERNANDES. Lygia de Oliveira. Estéticas negras e a escola: reflexões a partir de conversas com estudante do ensino médio. In: JÚNIOR, Jonas Alves da Silva; SALES, Sandra Regina \& SILVA. Tiago Dionísio da Silva (Orgs.). Direitos Humanos na Educação Básica: diálogos e interseccionalidades. Curitiba: CRV, 2019, p.127-139.

RIBEIRO, Ronilda Iyakemi. De Boca Perfumada a Ouvidos Dóceis e Limpos: Ancestralidades Africanas, Tradição Oral e Cultura Brasileira. Itineráios, Araraquara, No 13, 1998, p. 51-66.

RUI, Manoel. Eu e o outro. O invasor (ou em três poucas linhas uma maneira de pensar o texto). São Paulo: Centro Cultural, 1985. Conferência pronunciada no Encontro Perfil da Literatura Negra.

SANT’ANA, Antonio Olímpio. História e conceitos básicos sobre racismo e seus derivados. In: MUNANGA, Kabengele (org.). Superando o racismo no Brasil. Brasília: Ministério da Educação / Secretaria de Educação Fundamental, 2004, p. 39-67.

SILVA, Petronilha Beatriz Gonçalves. Aprender a conduzir a própria vida: dimensões do educar-se entre afrodescendentes e africanos. In: BARBOSA, Lúcia Maria de Assunção; SILVA, Petronilha Beatriz Gonçalves \& SILVÉRIO, Valter Roberto (Orgs.). De preto a afrodescendente: trajetos de pesquisa sobre relações étnico-raciais no Brasil. Brasília, UNESCO/São Carlos, EdUFSCar, 2003, p.181-197.

SODRÉ, Muniz. Reinventando @ cultura: Comunicação e seus produtos. Petrópolis: Vozes, 2001.

WALSH, Catherine. Pedagogias Decoloniais: práticas insurgentes de resistir, (re)existir y (re)vivir. Tomo I Serie Pensamiento Decolonial. Equador: Editora Abya Yala, 2013.

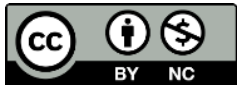

Este é um artigo de acesso aberto distribuído sob os termos da Licença Creative Commons Atribuição Não Comercial-Compartilha Igual (CC BY-NC- 4.0), que permite uso, distribuição e reprodução para fins não comerciais, com a citação dos autores e da fonte original e sob a mesma licença. 